\title{
Impact of converting enzyme inhibition on progression of chronic heart failure: results of the Munich Mild Heart Failure Trial
}

\author{
Franz X Kleber, Lisa Niemöller, Wittich Doering
}

\begin{abstract}
Objective-Neurohormonal activation has major impact on the pathophysiology of congestive heart failure. The Munich Mild Heart Failure Trial was designed to test the hypothesis that interference with the renin-angiotensin system by angiotensin converting enzyme inhibition favourably influences the natural history of heart failure.
\end{abstract}

Design and patients-170 patients, median New York Heart Association (NYHA) class II, were randomised to double blind treatment with $25 \mathrm{mg}$ captopril twice a day or placebo in addition to standard treatment for a median observation period of $2 \cdot 7$ years.

Main outcome measures-Progression of heart failure to NYHA class IV on an optimally adjusted standard treatment, death due to progressive heart failure, and sudden death.

Results-Heart failure progressed to class IV in nine patients $(10.8 \%)$ treated with captopril and in 23 patients (26.4\%) treated with placebo $(p=0.01)$. The mean survival time until this end point was 223 days longer in the captopril group (Kaplan-Meier life table analysis; $p=0.02$ ). Also, progressive deterioration to severe heart failure was a powerful predictor of total mortality and death from heart failure; $80 \%$ of deaths due to progressive heart failure occurred after this end point. There were fewer deaths caused by progressive heart failure in the captopril group than in the placebo group $(4$ v $11 ; p=0.10)$ but similar numbers of sudden deaths (11 $v$ 10). Progressive heart failure was the cause of death in $18 \cdot 2 \%$ of all deaths in the captopril group and $50 \%$ in the placebo group. Total heart failure events (the end point on which power calculation was based) were also more common in the placebo group (19 $v 32$ events) but not significantly so. Total mortality was similar to both groups (22 of $83 v 22$ of 87).

Conclusions-Angiotensin converting enzyme inhibition in conjunction with standard therapy early in the course of congestive heart failure slowed the progress of heart failure and thus favourably altered the natural history of the disease.
Chronic heart failure is a major cause of morbidity and admission to hospital and has a poor prognosis. Its therapeutic management has two goals: amelioration of symptoms (including improvement in functional capacity) and improvement of prognosis (including influence on progression of congestive heart failure and occurrence of sudden death). Symptoms can be improved by various treatments. ${ }^{1-3}$ Knowledge about improvement of prognosis is limited to a few drugs, especially the combination hydralazine and isosorbide dinitrate ${ }^{4}$ and converting enzyme inhibitors. ${ }^{56}$ Factors that have been shown to be associated with unfavourable prognosis in congestive heart failure include an increase in left ventricular volume, ${ }^{78}$ a low ejection fraction, ${ }^{9}$ high filling pressures, ${ }^{10}$ low exercise capacity, ${ }^{91}$ increased activity of the renin angiotensin system, ${ }^{12}$ and the sympathetic nervous system ${ }^{13}$ as well as low serum sodium concentration ${ }^{14} 15$ and an increased concentration of atrial natriuretic peptide. ${ }^{16} \mathrm{~A}$ favourable modification of these variables is therefore a major goal of treatment in congestive heart failure that should accompany symptomatic improvement. ${ }^{17} 18$

In the present trial we aimed to improve outcome by influencing the progression of congestive heart failure by adding captopril to the treatment regimen. We studied patients with mild (minimal to moderate) symptoms and used progression of congestive heart failure to NYHA class IV or death from heart failure as end points.

\section{Patients and methods}

\section{STUDY DESIGN}

This was a randomised, double blind, placebo controlled, parallel group, single centre trial in patients with congestive heart failure New York Heart Association (NYHA) functional class I-III on standard treatment. To avoid imbalance we randomly assigned patients to treatment with captopril or placebo within four groups defined by the duration of congestive heart failure at entry according to the criteria given below (group 1 up to four weeks, group 2 four weeks to one year, group 3 one year to three years, group 4 over three years). The progress of the study was followed by an independent advisory committee (see appendix I) and the hospital ethics committee also monitored questions of ethical relevance. 
PATIENTS

We studied patients (minimum age 18 years) with congestive heart failure NYHA functional class I, II, or III at entry into the trial. Patients in NYHA functional class IV were excluded. No drugs were stopped before entry. Treatment for heart failure with any drug other than converting enzyme inhibitors was allowed.

DIAGNOSIS OF CONGESTIVE HEART FAILURE

The diagnosis of congestive heart failure was based on history; thorough clinical examination by a cardiologist (usually FK); and laboratory work up, chest ' $x$ ray', electrocardiography, echocardiography when technically feasible, and either radionuclide ventriculography or coronary angiography with left ventricular cineangiography as clinically appropriate. We excluded patients with underlying cardiac diseases of unknown cause. Diagnosis of congestive heart failure was also confirmed by the presence of the modified Framingham criteria that served as entrance criteria (see below).

\section{ENTRANCE AND EXCLUSION CRITERIA}

Our entrance criteria were a slightly modified version of those of McKee et al (Framingham Study ${ }^{19}$ ) (table 1). The entrance criteria were not necessarily imposed at the time of randomisation in patients who had been saved by treatment of heart failure.

\section{BASELINE EXAMINATION AND FOLLOW UP EXAMINATIONS}

Baseline examination included cardiac and general history, physical examination, and laboratory and technical work up. Follow up examination included the history taken at regular three-monthly hospital visits. In the case of clinical events additional interim examinations were performed by the investigator. At the regular three monthly visits a standardised questionnaire about cardiac complaints was filled in by the investigators together with the patient. Compliance was checked by a tablet count. At each visit, medication for another three months was given to the patient. A detailed evaluation of follow up symptoms and laboratory results will be presented elsewhere.

TEST MEDICATION, CONCOMITANT MEDICATION, AND GENERAL MEASURES

Captopril and placebo were administered in increasing doses (from $6.25 \mathrm{mg}$ to $25 \mathrm{mg}$ twice a day). When no side effects occurred the maximum dose was reached in three days. The maximum dose was $50 \%$ when serum creatinine was $>265 \mu \mathrm{mol} / 1$ and $25 \%$ when it was $>440 \mu \mathrm{mol} / \mathrm{l}$.

Concomitant medication was introduced and continued according to therapeutic need. No attempt was made by the investigators to influence concomitant medication. If a patient's physician considered that angiotensin converting enzyme inhibitor treatment was necessary we reviewed the patient to see whether heart failure had become severe (the second end point).

Before entry all patients were advised about a moderately salt-restricted diet, weight reduction if necessary, appropriate rest periods, and restricted physical activity. We gave our patients detailed information about the pathophysiology of their disease and its potential sequelae. Psychological reassurance at entry and at each visit was mandatory and a telephone in service staffed by a cardiologist was provided for all patients and family physicians with urgent problems or questions.

\section{END POINTS}

Two end points were pre-defined in the study protocol, both end points together were used to calculate the sample size (see Statistical Analysis): death due to heart failure, with subclassification into sudden death (definition see below) and death due to progressive heart failure (definition see below); deterioration of heart failure to severe heart failure (NYHA

Table 1 Entrance criteria and exclusion criteria

\begin{tabular}{|c|c|c|}
\hline \multicolumn{2}{|l|}{ Entrance criteria } & \multirow[b]{2}{*}{ Exclusion criteria } \\
\hline Major & Minor & \\
\hline Paroxysmal dyspnoea or orthopnoea & Ankle oedema & Heart failure NYHA Class IV at entry \\
\hline Neck vein distension & Night cough & $\begin{array}{l}\text { Malignancies or other diseases that greatly affected } \\
\text { life expectancy }\end{array}$ \\
\hline $\begin{array}{l}\text { Rales (more than } 10 \mathrm{~cm} \text { from the base of the } \\
\text { lungs) }\end{array}$ & Dyspnoea on exertion & $\begin{array}{l}\text { Haemodialysis or peritoneal dialysis for chronic } \\
\text { renal failure }\end{array}$ \\
\hline Cardiomegaly on chest $x$ ray & Hepatomegaly & Connective tissue diseases \\
\hline $\begin{array}{l}\text { Echocardiographic left ventricular end diastolic } \\
\text { diameter } \\
\text { more than } 60 \mathrm{~mm} \text { or left ventricular end } \\
\text { systolic diameter } \\
\text { more than } 45 \mathrm{~mm}\end{array}$ & Pleural effusion & $\begin{array}{l}\text { Concomitant immunosuppressive therapy } \\
\text { Known renal artery stenosis } \\
\text { Gestation and lactation }\end{array}$ \\
\hline Acute pulmonary oedema & Tachycardia of at least 120 beats/min & Significant aortic stenosis \\
\hline$S_{3}$ gallop & $\begin{array}{l}\text { Weight loss of } \geqslant 4.5 \mathrm{~kg} \text { after introduction of } \\
\text { treatment for congestive heart failure where } \\
\text { factors other than treatment for congestive heart } \\
\text { failure could have contributed to the weight loss }\end{array}$ & Significant mitral stenosis \\
\hline Venous pressure $>16 \mathrm{~cm} \mathrm{H}_{2} \mathrm{O}$ & & Myocardial infarction within three weeks \\
\hline $\begin{array}{l}\text { Weight loss of } 4.5 \mathrm{~kg} \text { or more due to introduction } \\
\text { of treatment for congestive heart failure }\end{array}$ & & $\begin{array}{l}\text { Systolic blood pressure }<95 \mathrm{~mm} \mathrm{Hg} \\
\text { Uncontrolled hypertension }\end{array}$ \\
\hline
\end{tabular}

Two major or one major and two minor criteria had to be fulfilled. 
Table 2 Severity of congestive heart failure at entry

\begin{tabular}{|c|c|c|c|}
\hline & Captopril & Placebo & $p$ \\
\hline $\begin{array}{l}\text { Presence of major entrance criteria (\%) (mean (SD)) } \\
\text { Presence of minor entrance criteria }(\%) \text { (mean (SD)) } \\
\text { NYHA functional class (\% of patients): }\end{array}$ & $\begin{array}{l}45 \cdot 8(21 \cdot 6) \\
33 \cdot 0(18 \cdot 6)\end{array}$ & $\begin{array}{l}49 \cdot 3(19 \cdot 2) \\
34 \cdot 9(20 \cdot 6)\end{array}$ & $\begin{array}{l}\text { NS } \\
\text { NS }\end{array}$ \\
\hline $\begin{array}{l}\text { II } \\
\text { III } \\
\text { Cardiothoracic ratio (\%) (mean (SD)) } \\
\text { M mode echocardiographic diameter (mm) (mean (SD)): }\end{array}$ & $\left.\begin{array}{l}27 \\
52 \\
21\end{array}\right\} 1.94(0.69)$ & $\left.\begin{array}{l}25 \\
48 \\
26\end{array}\right\} 2 \cdot 01(0 \cdot 72)$ & $\begin{array}{l}\text { NS } \\
\text { NS }\end{array}$ \\
\hline $\begin{array}{l}\text { Diastolic } \\
\text { Systolic } \\
\text { Left ventricular ejection fraction }{ }^{\star} \\
\text { Diuretic score } \dagger\end{array}$ & $\begin{array}{l}60 \cdot 9(6 \cdot 7) \\
47 \cdot 9(9 \cdot 4) \\
35 \cdot 0(13 \cdot 1) \\
3 \cdot 2(3 \cdot 9)\end{array}$ & $\begin{array}{l}63 \cdot 5(7 \cdot 0) \\
49 \cdot 6(9 \cdot 0) \\
34 \cdot 6(13 \cdot 9) \\
3 \cdot 6(4 \cdot 1)\end{array}$ & $\begin{array}{l}0 \cdot 027 \\
\text { NS } \\
\text { NS } \\
\text { NS }\end{array}$ \\
\hline
\end{tabular}

^By contrast angiography or radionuclide ventriculography.

† Score represents $13.33 \mathrm{mg}$ frusemide or $25 \mathrm{mg}$ hydrochlorothiazide.

functional class IV) despite optimal adjusted concomitant treatment (definition see below).

Before we broke the code all end points were defined and all deaths classified. Sudden death was defined as witnessed unexpected death within an hour of the onset of symptoms, and not occurring in a patient with NYHA class IV heart failure. ${ }^{20}$ Death in progressive heart failure was defined as death in cardiogenic shock or pulmonary oedema after a period of severe heart failure. The second end point (deterioration to class IV on optimal concomitant treatment) was defined by the following criteria: congestive heart failure NYHA class IV with symptoms at rest or on minimal exertion in the absence of concomitant problems leading to deterioration (for example, upper or lower airway infections, suboptimal rate control in atrial fibrillation, bradycardia, ventricular extrasystoles compromising pump function). These severe symptoms had to persist despite optimal adjustments of concomitant treatment and recompensation with digitalis, diuretics, nitrates (and hydralazine if appropriate) in suitable doses had to be unsuccessful. A transient deterioration into class IV heart failure that was easily recompensated by standard measures was not accepted as a sufficient end point.

When the end point of class IV heart failure was reached, treatment with captopril ( $25 \mathrm{mg}$ $50 \mathrm{mg}$ twice a day) was started and mortality follow up was continued (intention to treat). Unwitnessed deaths, other cardiac, cardiovascular, or non-cardiovascular deaths were not categorised. All deaths were reported to the independent advisory committee and all instances of deterioration were verified independently by an end point review board at the request of the advisory committee.

STATISTICS AND SAMPLE SIZE CALCULATION The results of the Framingham Study, which showed a $37.5 \% 2.5$ year mortality in patients with the first clinical signs of heart failure, led us to expect at least $37.5 \%$ heart failure deaths and/or deteriorations to NYHA class IV. We planned to detect a reduction of these events by treatment of $20 \%-17 \cdot 5 \%$. The sample size was calculated with an overall type I error rate (alpha) of 0.05 and type II error rate (beta) of 0.20 (Fisher's exact test, two tailed). Under these specified conditions the calculated sample size was 170 patients.

To avoid imbalances in the outlook for the two treatment groups randomisation was stratified by duration of heart failure before the trial. Therefore randomisation was performed in four strata of 100 treatment allocations. Patients were allocated to the next treatment in the stratum depending on their duration of heart failure.

To compare the results in the two treatment groups we used the same statistical method as we used to calculate sample size (Fisher's exact test, two tailed). The overall type I error rate for the comparison of treatment effects on the primary end point (heart failure death and/or progression of heart failure) was fixed at alpha $=0.05$.

In addition, we analysed both constituents of the primary end point separately. For this comparison an adjusted alpha type I error rate of alpha $=0.025$ was deemed to be significant. The power of a significant test result was calculated on the basis of the appropriate type I error rate.

The confirmatory comparison of the treatment results was performed according to the intention-to-treat approach. In addition to comparisons of crude mortality rates by Fisher's exact test, Kaplan-Meier life table analyses were performed and tested by the generalised Wilcoxon test.

\section{INFORMED CONSENT}

Patients were asked to participate at least one day before randomisation after they were given detailed written information. Informed consent was obtained from each patient.

\section{Results}

DEMOGRAPHIC DATA

One hundred and seventy patients (128 male

Table 3 Premature treatment withdrawals

\begin{tabular}{lll}
\hline Reason & Captopril $(n)$ & Placebo $(n)$ \\
\hline Compliance & 12 & 8 \\
Hypotension & 6 & 3 \\
Taste disturbance & 1 & 1 \\
Cough & 1 & 0 \\
Palpitation & 1 & 0 \\
Hypertension & 1 & 1 \\
Non-cardiac diseases $\dagger$ & 2 & 0 \\
\hline
\end{tabular}

*Because it was impossible to control blood pressure with drugs other than angiotensin converting enzyme inhibitorsthat is the other antihypertensive drugs were ineffective or had major side effects.

tDisabling rheumatoid arthritis and severe gastric ulcer in one patient and stroke and inability to swallow in one patient. 
Table 4 Heart failure events

\begin{tabular}{lcl}
\hline End point & Captopril/placebo & $p$ (Fisher's exact test) \\
\hline NYHA IV deterioration & $9 / 23$ & $0 \cdot 010^{\star}$ \\
Total deaths & $22 / 22$ & $\mathrm{NS}$ \\
Heart failure deaths: & $11 / 10$ & $\mathrm{NS}$ \\
Sudden death & $4 / 11$ & $0 \cdot 104$ \\
Pump failure death & $19 / 32$ & 0.065 \\
All heart failure events & $3 / 0$ & - \\
Non-heart failure deaths: & $1 / 1$ & - \\
Reinfarctions & $1 / 0$ & - \\
Stroke & $1 / 0$ & - \\
Malignancy & $1 / 0$ & - \\
Respiratory failure & & \\
Pulmonary embolism & & \\
\hline Power $=57 \%(\alpha=0.025)$. & &
\end{tabular}

and 42 female; mean age 62.4 ) entered the study between February 1985 and October 1989. Patients were randomised to captopril $(n=83)$ or placebo ( $n=87$ ). Most were randomised within group 2 ( $n=109$; see study design). Patients were followed up for a median of $2 \cdot 7$ years.

\section{AETIOLOGY AND SEVERITY OF CONGESTIVE HEART FAILURE}

Coronary artery disease was the leading cause of congestive heart failure, with prior myocardial infarction in $69 \%$ (coronary artery disease was the sole reason for congestive heart failure in $58 \%$ ). Hypertensive heart disease was present in $12 \%$ and dilated cardiomyopathy in $20 \%$. Congestive heart failure of other origin was found in $6 \%$ of patients. There was atrial fibrillation in $14.7 \%(25 / 170)$ of patients. The percentage of patients with atrial fibrillation was similar in patients in whom progressive heart failure developed $(5 / 32=15.6 \%)$ or who died later $(6 / 44=13 \cdot 6 \%)$. Table 2 shows the severity of congestive heart failure. Most patients had mild symptoms while they were being treated though many had a history of more severe symptoms earlier. NYHA functional classes were evenly distributed among both groups with $72 \%$ of patients being in either NYHA class I or II. Left ventricular size

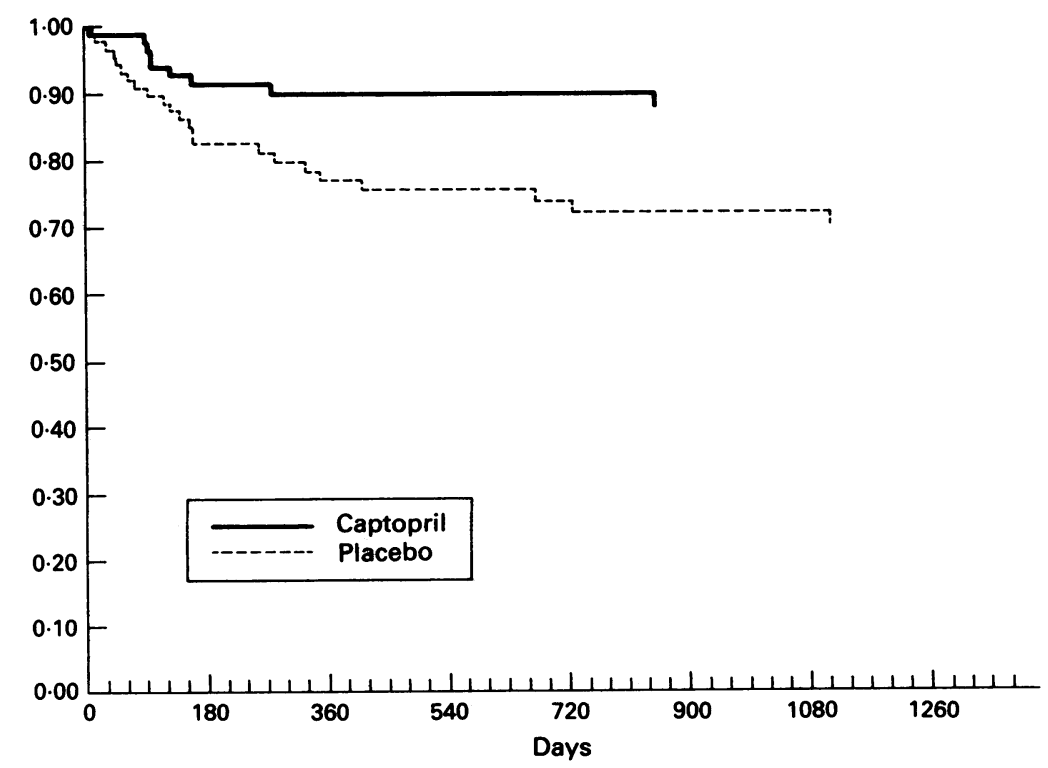

Figure 1 Survival time analysis (Kaplan-Meier) for the end point "progression of heart failure to NYHA class IV on optimal adjusted therapy". and function were well outside the normal range, and the cardiothoracic ratio on the chest $x$ ray was increased. Both groups were very similar except for one echocardiographic variable (table 2).

\section{CONCOMITANT MEDICATION AT ENTRY}

At entry $78.8 \%$ of patients were being treated with diuretic drugs: $42.4 \%$ on frusemide (mean dose $81 \mathrm{mg}$ ), $27 \cdot 1 \%$ on hydrochlorothiazide (mean dose $35 \mathrm{mg}$ ), and $9.3 \%$ on other diuretics. At entry, $59 \%$ of the patients were taking digitalis treatment (usually digoxin), $59 \%$ nitrates, $23 \% \beta$ blockers, $23 \%$ antiarrhythmic drugs, and $23 \%$ calcium antagonists (usually verapamil) for rate control of atrial fibrillation. All concomitant therapy was evenly distributed at entry in both groups except that nitrates tended to be used more often in the captopril group at entry (59 $v 41$ patients; $p=$ 0.03).

\section{PREMATURE WITHDRAWALS OVER THE TOTAI} STUDY PERIOD

A few patients had to be withdrawn from randomised therapy because of side effects, concomitant diseases, or lack of compliance (table 3). Follow up of all patients who were withdrawn from the study was continued for evaluation of end points (intention to treat analysis).

\section{DEATHS}

Twenty four (25.9\%) patients died, 22 patients in each group, and $81.8 \%$ of deaths were due to heart failure: $34 \cdot 1 \%$ to progressive heart failure and $47.7 \%$ to sudden death. Other cardiovascular death occurred in $13.6 \%$ and noncardiovascular death accounted for $4.5 \%$ of all deaths. Table 4 shows the distribution of deaths and other events within the two treatment groups. There was a difference between the groups in death from progressive heart failure but not in sudden death. Half the deaths in the placebo group were due to progressive heart failure but only $18.2 \%$ of those in the captopril group. Most non-sudden deaths occurred in hospital and most sudden deaths occurred outside the hospital.

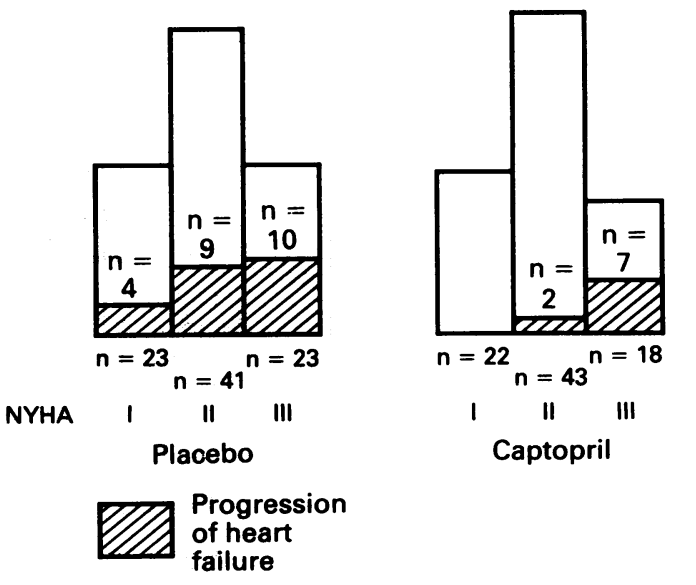

Figure 2 Contribution of patients in different stages of heart failure (according to NYHA functional class at entry) to the group of patients with progression of heart failure (shaded bars) in the placebo and the captopril treated group. 


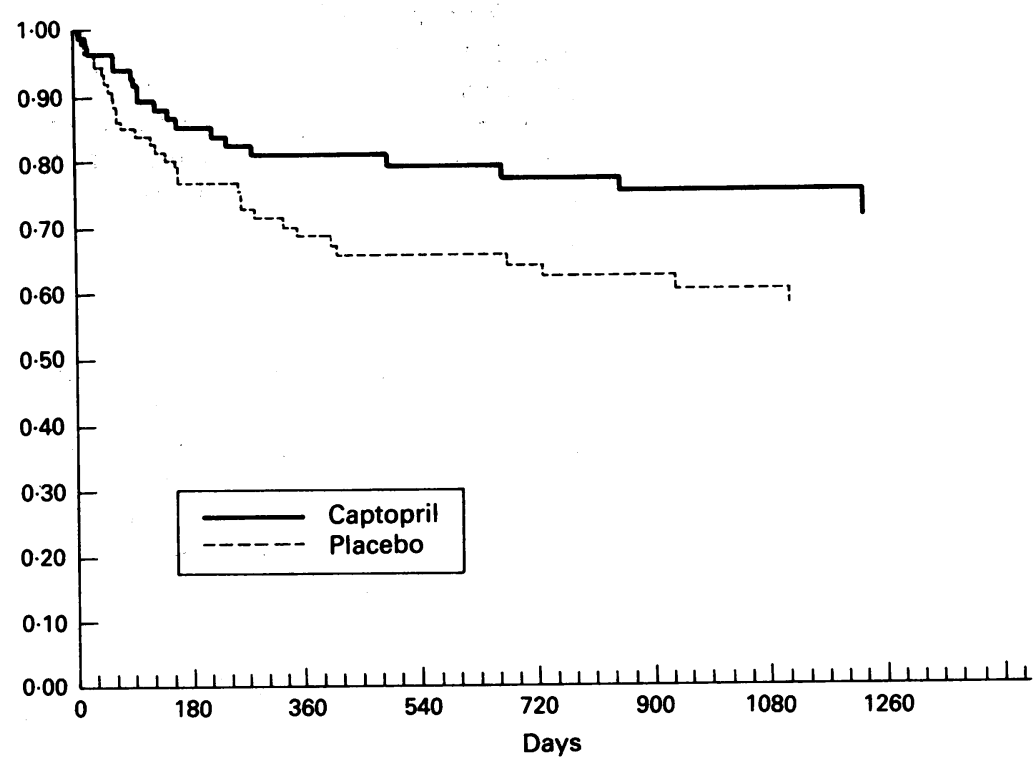

Figure 3 Survival time analysis (Kaplan-Meier) for all heart failure events including death due to progressive heart failure, sudden death, and progression of heart failure to NYHA class IV. points. The mean event-free survival time in this analysis was prolonged by 292 days (life table $\mathrm{p}$ level $=0.071$ ). Table 5 gives the cumulative event rate for both end points after a year and at the end of the study.

\section{Discussion}

DEMOGRAPHIC DATA

This study followed 170 patients for a median observation period of 2.7 years (three months to five years). The main question of the trial was whether addition of angiotensin converting enzyme inhibitors to standard treatment might favourably influence the prognosis of congestive heart failure. Progression of heart failure to refractory NYHA class IV or death due to heart failure were defined. Patients in both groups were similar with respect to age, observation period, heart and left ventricular size, and NYHA class, as well as concomitant treatment.

\section{PROGNOSTIC CRITERIA}

When this trial was designed in 1984 an end point in addition to death was planned for two reasons: by 1984 symptoms of severe heart failure had already been shown to be improved by angiotensin converting enzyme inhibition in several trials ${ }^{21-23}$ and we thought that for this reason angiotensin converting enzyme inhibitor treatment should not be withheld from these patients. This point of view was confirmed by the results of the CONSENSUS trial $^{5}$ and made a later protocol amendment for ethical reasons unnecessary. Though not good, ${ }^{19}$ prognosis in mild congestive heart failure is much better than in severe congestive heart failure, ${ }^{1024}$ and the transition of mild forms to the most severe forms had to be recognised as a prognostically important deterioration.

The introduction of additional end points can reduce sample size, but additional end points are less reliable indicators of extended life expectancy than death itself. However, there are several well recognised determinants of poor prognosis in congestive heart failure, ${ }^{9}$ that have been proposed for prognostic studies and are being used as additional end points in ongoing trials (SAVE trial, M Pfeffer, personal communication). We used NYHA class IV heart failure as an additional end point. NYHA class IV heart failure is defined more unequivocally and inter-observer disagreement does not occur as often as with the other grades of severity. To define NYHA class IV even more strictly we added the term "under optimal adjusted concomitant therapy."

The introduction of a second end point into a prognosis trial, however, implies that death

\begin{tabular}{llllll}
\hline Observed end point & $\begin{array}{l}\text { One year } \\
\text { Captopril/placebo }\end{array}$ & $\begin{array}{l}\text { End of study } \\
\text { Captopril/placebo }\end{array}$ & $p$ (life table) \\
\hline $\begin{array}{lllll}\text { Progression of heart failure to NYHA IV under } \\
\text { optimal adjusted concomitant therapy }\end{array}$ & 10.1 & 23.0 & 12.2 & $30 \cdot 3$ & 0.0108 \\
$\begin{array}{l}\text { Death } \\
\text { Heart failure, death, or NYHA IV }\end{array}$ & 16.4 & 4.6 & 37.8 & $39 \cdot 8$ & NS \\
\hline
\end{tabular}


after the first end point (after deterioration to NYHA class IV) regularly occurs after the start of active treatment (that is, with an angiotensin converting enzyme inhibitor). Thus analysis on the basis of intention to treat might be appropriate for the first end point only.

\section{END POINTS}

\section{Mortality}

In the placebo group one year mortality was $15 \%$, two year mortality $19 \%$, three year mortality $25 \%$ and five year mortality was $40 \%$. These data show a lower mortality than in the Framingham study, ${ }^{19}$ which is in part explained by the introduction of angiotensin converting enzyme inhibitor treatment after the occurrence of the end point of NYHA class IV heart failure (see below).

Overall mortality was not different in our two treatment groups. There are several explanations for this: patients reaching the second end point (deterioration to NYHA class IV) were regularly switched to active treatment. Treatment with angiotensin converting enzyme inhibitor therapy in class IV heart failure has been shown to reduce mortality ${ }^{5}$ and this would obscure the effects on mortality in our trial. Patients with congestive heart failure are threatened by two major causes of death: sudden death and death due to progressive heart failure. Sudden death in our trial was not influenced by captopril (see below) and it was the major mode of death (see below).

The calculated sample size in this trial (170 patients) was based on heart failure events including deteriorations and deaths due to heart failure. This study does not have enough power to demonstrate effects on mortality alone or mortality due to specific causes (for example, sudden death).

\section{Sudden death}

Angiotensin converting enzyme inhibitors might decrease the likelihood of sudden death by improving left ventricular function, by decreasing filling pressures and peripheral vascular resistance, by avoiding potassium and magnesium deficits, and by the effects on reperfusion arrhythmias (shown experimentally). ${ }^{25}$ In our trial, however, we found that captopril did not affect sudden death. Eleven sudden deaths occurred in the captopril group and 10 in the placebo group. This lack of difference on sudden cardiac death could be attributed to the low dose of captopril we administered. Trials that showed a significant reduction in ventricular extrasystoles by angiotensin converting enzyme inhibitor treatment ${ }^{26-28}$ used higher doses. However, serum potassium concentrations increased significantly in the captopril group but not in the placebo group, and the increase in noradrenaline with increasing severity of congestive heart failure was blunted in patients treated with captopril (unpublished data). These observations support the suggestion that the dose of $25 \mathrm{mg}$ twice a day is an effective dose. Thus our trial suggests that the potential of angiotensin converting enzyme inhibitors to prevent sudden cardiac death might have been overestimated. The results of the CONSENSUS trial' ${ }^{5}$ accord with this.

\section{Death due to progressive heart failure}

Death due to progressive heart failure occurred more often in the placebo group than in the captopril group (4 $v 11$ patients). This difference was not significant $(p=0 \cdot 10)$; however, the subset of patients studied was small.

Progression of heart failure to NYHA Class IV Severe worsening of heart failure was considerably suppressed by captopril treatment. Deterioration to NYHA class IV has prognostic relevance, ${ }^{102429}$ and avoidance of decompensation by non-pharmacological means has been shown to improve outcome. ${ }^{30}$ The introduction of active treatment at this point, however, obscured the influence on mortality. Nevertheless, captopril significantly prevented both symptomatic deterioration and life-threatening progression of disease.

Furthermore, progression to class IV heart failure was a powerful predictor of outcome. Mortality in this subset was 2.5 times higher than in the remaining patients. Deterioration to class IV was also most predictive for death in progressive heart failure, whereas it was not a good predictor of sudden death. Only five of the 21 patients who died suddenly died after deterioration of heart failure. Overall this suggests that our definition of deterioration of heart failure to class IV on optimal adjusted concomitant treatment can serve as a surrogate for death from progressive heart failure and obviously reflects progression of heart failure.

Captopril was more effective in preventing the progression of heart failure in patients with NYHA class I or II at entry than in patients with NYHA class III. About half the patients in whom the disease progressed had heart failure in NYHA class III at entry (fig 2).

Possibly because many patients reached end point 2 (almost as many as reached end point 1 ) a considerable number of patients died after active treatment was started. This was 2.5 times more common in the placebo group than in the captopril group. This reduced the difference between the two groups so that the difference in the combined end points was not significantly different (life table $p=0.071$, Fisher's exact test $p=0.065$ ).

Progression of heart failure is associated with progressive left ventricular dilatation, ${ }^{81}$ which in turn is associated with outcome. ${ }^{183132}$ Though several experimental ${ }^{334}$ and clinical $^{35} 36$ trials showed that angiotensin converting enzyme inhibition had a beneficial effect on progressive left ventricular dilatation after myocardial infarction our trial does not establish or confirm the hypothesis that progression of heart failure is necessarily due to progressive pump dysfunction or left ventricular dilatation. It does, however, show that progressive heart failure is a predictor of poor outcome and that progression of heart failure can be influenced favourably by angiotensin converting enzyme inhibition. Thus earlier treatment of congestive failure with converting enzyme inhibitors offers therapeutic benefits over and above the standard treatment of refractory congestive heart failure. 
Appendix I: Advisory Committee Members

J Follath, $\mathrm{MD}$,

Division of Internal

Medicine,

Kantonsspital Basel,

Petersgraben,

CH-4003 Basel,

Switzerland

J Holtz, MD, Insitute for Applied Physiology,

Hermann-Herder-Strasse

7

D-7800 Freiburg,

Federal Republic of

Germany

$H$ Jahrmärker, $M D$, Faculty of Medicine, Ludwig-Maximilians University, Munich, Karl-Valentin-Strasse 9 D-8022 Grünwald, Federal Republic of Germany

Chairman:

H Just, MD,

Division of Cardiology,

Albert Ludwigs

University,

Hugstetter Strasse 55

D-7800 Freiburg,

Federal Republic of

Germany

M Schumacher, MD

Institute for Medical

Biometry and

Informatics,

Albert Ludwigs

University,

Stefan-Meier-Strasse 26

D-7800 Freiburg,

Federal Republic of

Germany

Appendix II;

Members of the End

Point Review Board

H Drexler, MD,

Division of Cardiology,

Albert Ludwigs

University,

Hugstetter Strasse 55,

D-7800 Freiburg,

Federal Republic of

Germany

F Burkart, MD,

Division of Cardiology,

Kantonspital Basel,

Petersgraben,

CH-4031 Basel,

Switzerland

$\mathrm{K}$ Theisen, $\mathrm{MD}$,

Division of Cardiology,

Ludwig-Maximilians

University,

Ziemssenstrasse 1 ,

D-8000 München 2

Federal Republic of

Germany
LIMITATIONS OF THIS TRIAL

This trial aimed to improve outcome in heart failure (reduction of deaths due to heart failure and slowing of progression of heart failure). The study design and sample size prevented our investigating the hypothesis that angiotensin converting enzyme inhibitors improve survival longevity whatever the cause of death. Furthermore, part of the crucial difference occurred in an end point that might be viewed as less reliable than death. However, the difference in death due to progressive heart failure $(11 / 87 v 4 / 83)$ and in deterioration to class IV heart failure $(23 / 87 v 9 / 83)$ was considerable and was the reason why the advisory committee discouraged a double blind extension of this study. Deterioration to class IV is not an ideal index of progression of heart failure. However, progressive symptoms despite optimal concomitant therapy characterise the relentless deteriorating course of congestive heart failure and therapeutic strategies designed to avoid decompensations of congestive heart failure have been shown to improve considerably prognosis in an open trial. ${ }^{30}$

Our study did not aim to demonstrate improvement in exercise capacity, because several randomised controlled studies have already consistently shown a positive effect of angiotensin converting enzyme inhibition on exercise capacity. ${ }^{21} 237$ Meanwhile, however, exercise time has been shown to be an independent predictor of mortality, ${ }^{9}$ which strengthens the interest in exercise capacity. This study is limited because exercise time and maximal oxygen consumption were not measured. It is unlikely that improvement in exercise capacity is a measure of symptomatic benefit or of prognostic relevance in patients in NYHA class I and II (that is $72 \%$ of our patients) because these patients are largely symptomfree in everyday life.

We studied patients in NYHA functional classes I, II, and III, which introduced some heterogeneity into the population under investigation. The entrance criteria did not include NYHA class, but were derived from the Framingham criteria and the inclusion of patients with dissimilar severity gave the opportunity to study treatment efficacy in various subgroups. The mean and median NYHA class II and the relatively low one year mortality rate $(15 \%)$ are typical of a population with fairly mild heart failure, though patients with moderate heart failure were definitely included as well.

The results of the CONSENSUS trial and the present study make it unlikely that treatment with converting enzyme inhibitor influences sudden death. Neither had enough power, however, to demonstrate a lack of influence on sudden death alone, rather than progressive heart failure. It might be more appropriate and more ethical to study patients with left ventricular dysfunction without overt heart failure to further investigate this question.

This trial was performed at one hospital. Though bias in the assignment of end points is not possible in a double blind trial, personal errors have more effect than in a multicentre trial. However, the critical end point "deterioration to NYHA class IV" was reevaluated by an independent review board. A monocentre trial is more likely to be consistent in terms of evaluation methods and diagnostic criteria.

We conclude that angiotensin converting enzyme inhibitor treatment in conjunction with standard treatment slows the progress of congestive heart failure and thus is able to improve prognosis, though it does not reduce the risk of sudden cardiac death. Because of the design of our study we do not know whether overall mortality is influenced by these drugs in mild congestive heart failure. Three trials are underway to answer this question: the VHeFT II, the SOLVD, and the SAVE trial. Our results indicate that angiotensin converting enzyme inhibitor treatment should be considered for any patient who requires medical treatment for symptomatic congestive heart failure.

We thank the members of the advisory committee (see appendix I) and the review board (see appendix II) as well as the former I) We We also greatly appreciate the cooperation of the other medica divisions at our institution and also their physicians in chief, $D$ Helmut Mehnert, Dr Horst Kuhlmann, Dr Werner Kaboth, Dr Dieter Eichenlaub; the organisational assistance of Mrs Evelyn Hitzke; and the secretarial expertise of Ms Patricia Hodges. We thank the nurses and technicians of the Krankenhaus MünchenSchwabing for their support and for sharing in our enthusiasm.

This study was in part supported by a grant from the Squibbvon Heyden GmbH, Germany.

1 The Captopril-Digoxin Multicenter Research Group. Comparative effects of therapy with captopril and digoxin in patients with mild to moderate heart failure. JAMA 1988;259:539-44.

2 DiBianco R, Shabatai R, Kostik W, Moran J, Schlant T, Wright R, for the Milrinone Multicentre Trial Group. A comparison of oral milrinone, digoxin, and their combination in the treatment of patients with chronic heart failure. tion in the treatment of patients

3 Bayliss J, Norell M, Canepa-Anson R, Sutton G, PooleWilson $P$. Untreated heart failure: clinical and neuroendocrine effects of introducing diuretics. Br Heart $\mathrm{J}$ 1987;57:17-22.

4 Cohn JN, Archibald DG, Ziesche S, Franciosa JA, Harston WE, Tristani FE, et al. Effect of vasodilator therapy on mortality in chronic congestive heart failure. Results of a Veterans Administration cooperative study. N Engl J Med 1986;314:1547-52.

5 The CONSENSUS Trial Study Group. Effects of enalapril on mortality in severe congestive heart failure. $N \mathrm{Engl} \mathrm{J}$ Med 1987;316:1429-35.

6 Newmann TJ, Maskin CS, Dennick IG, Meyer JH, Hallows BG, Cooper WH. Effects of captopril on survival in patients with heart failure. Am J Med 1988; 84(suppl A):140-4.

7 Jeremy RW, Allmann KC, Bautowich G, Harris PJ. Patterns of left ventricular dilatation during the six months after myocardial infarction. J Am Coll Cardiol 1989;13:304-10.

8 Hammermeister KE, DeRouen TA, Dodge HT. Variables predictive of survival in patients with coronary disease; Selection by univariate and multivariate analyses from the clinical electrocardiographic, exercise, arteriographic, and quantitative angiographic evaluations. Circulation 1979;59:421-30.

9 Cohn JN, Archibald DG, Francis GS, Ziesche S, Franciosa JA, Harston WE, et al. Veterans Administration cooperative study of vasodilator therapy of heart failure: influence of pre-randomization variables on the reduction of mortality by treatment with hydralazine and isosorbide dinitrate. Circulation 1987;75(suppl IV):49-54.

10 Franciosa JA. Why patients with heart failure die: hemodynamic and functional determinants of survival. Circula tion 1987;75(suppl IV):20-7.

11 Gradman A, Deedwania P, Cody R, Massie B, Packer M Pitt B, et al, for the Captopril-Digoxin Study Group. Predictors of total mortality and sudden death in mild to moderate heart failure. J Am Coll Cardiol 1989;14:564-70.

12 Rockman HA, Juneau C, Chatterjee K, Rouleau JR. Longterm predictors of sudden and low output death in chronic congestive heart failure secondary to coronary artery disease. A J Cardiol 1989;164:1344-8.

13 Cohn JN, Levine B, Olivari MT, Garberg V, Lura D, Francis GS, et al. Plasma norepinephrine as a guide to 
prognosis in patients with chronic congestive heart failure. N Engl J Med 1984;311:891-923.

14 Lee WH, Packer M. Prognostic importance of serum sodium concentrations and its modification by converting-enzyme inhibition in patients with severe chronic heart failure. Circulation 1986;73:257-67.

15 Packer M, Medina N, Yushak M. Correction of dilutional hyponatremia in severe chronic heart failure by converting-enzyme inhibition. Ann Intern Med 1984;100:782-9.

16 Gottlieb SS, Kukin ML, Ahern D, Packer M. Prognostic importance of atrial natriuretic peptide in patients with importance of atrial natriuretic peptide in patients with

17 ACE inhibitors after myocardial infarction. Lancet 1989;ii:1133-4

18 Kleber FX. ACE Inhibitors after myocardial infarction. Lancet 1990;i:295, 984.

19 McKee PA, Castell WP, McNamara PM, Kannel WB. The natural history of congestive heart failure: the Framingham study. N Engl J Med 1971;285:1441-6.

20 Hinkle LE Jr, Tzvi Thaler $H$. Clinical classification of cardiac deaths. Circulation 1982;65:457-64.

21 Captopril Multicenter Research Group. A placebo-controlled trial of captopril in refractory chronic congestive heart failure. J Am Coll Cardiol 1983;2:755-63.

22 Cleland JGF, Dargie HJ, Hodsman GP, Ball SG, Robertson JIS, Morton JJ, et al. Captopril in heart failure: a double JIS, Morton JJ, et al. Captopril in heart failure:

23 Kramer BL, Massie BM, Topic N. Controlled trial of captopril in chronic heart failure: a rest and exercise hemodynamic study. Circulation 1983;67:807-16.

24 Wilson JR, Schwartz JS, St John Sutton M, Ferraro LN, Horowitz N, Reichel N, et al. Prognosis in severe heart failure: relation to hemodynamic measurements and ventricular ectopic activity. J Am Coll Cardiol 1983;3:403-10.

25 van Gilst WH, de Graeff PA, Wesseling H, de Langen CDJ. Reduction of reperfusion arrhythmias in the ischemic isolated rat heart by angiotensin converting enzyme inhibitors: a comparison of captopril, enalapril, and HOE 498. J Cardiovasc Pharmacol 1986;8:722-8.

26 Cleland JGF, Dargie HJ, Ball SG, Gillen G, Hodsman GP, Morton JJ, et al. Effects of enalapril in heart failure: Morton JJ, et al. Effects of enalapril in heart failure: a double blind study of effects on exercise performance, renal 1985;54:305-12.
27 de Langen CDJ, de Graeff PA, van Gilst WH, Bel KJ Kingma JH, Wesseling $\mathrm{H}$. Effects of angiotensin II and captopril on inductible sustained ventricular tachycardia two weeks after myocardial infarction in the pig. Cardiovasc Pharmacol 1989;13:186-91.

28 Webster MWI, Fitzpatrick MA, Nicholls MG, Ikram H, Wells $\mathrm{E}$. Effect of enalapril on ventricular arrhythmias in congestive heart failure. Am J Cardiol 1985;56:566-9.

29 Chatteriee K, Parmley WW, Cohn JN, Levine TB, Awan NA, Mason DT, et al, for the Captopril multicenter research group. A cooperative multicenter study of capresearch group. A cooperative multicenter study of captopril in congestive heart failure: hemodynamic effects

30 Bertel O, Conen D, Schwarz U, Besch W, Dubach UC. Verbessert die engmaschige Kontrolle und TherapieAnpassung die Prognose bei schwer herzinsuffiziente Patienten? Schweiz Med Wochenschr 1985;115:1820-3.

31 Kleber FX, Einwang HP, Kronski D, Ohly A, Osterkorn K, Doering W. Progrediente linksventrikuläre Dilatation nach Vorderwandinfarkt als Determinante für die Entwicklung einer Herzinsuffizienz. $Z$ Kardiol 1990;79:1-7.

32 White HD, Norris RM, Brown MA, Brandt PWT, Whitlock RML, Wild CJ. Left ventricular end-systolic volume as the 'major determinant of survival after recovery from myocardial infarction. Circulation 1987;76:44-51.

33 Pffecardial infarction. Circulation 1987; experimental myocardial infarction: beneficial effects of experimental myocardial infarction: beneficial effects of 1985-term therap 12 .

34 Sweet CS, Emmert SE, Stabilito II, Ribeiro LG. Increased survival in rats with congestive heart failure treated with nalapril. J Cardiovasc Pharmacol 1987;10:636-42.

35 Pfeffer MA, Lamas GA, Vaughan DE, Parisi AF, Braunwald E. Effect of captopril on progressive ventricular dilatation fter anterior myocardial infarction. $N \mathrm{Engl} J \mathrm{Med}$ 1988;319:80-6.

36 Sharpe N, Smith H, Murphy J, Hannan S. Treatment of patients with symptomless left ventricular dysfunction after myocardial infarction. Lancet 1988; i:255-9.

37 Sharpe DN, Murphy J, Coxon R, Hannan SF. Enalapril in patients with chronic heart failure: a placebo-controlled, patients with chronic heart failure: a placebo-controlled,
randomized, double-blind study. Circulation 1984;70:271-8. 